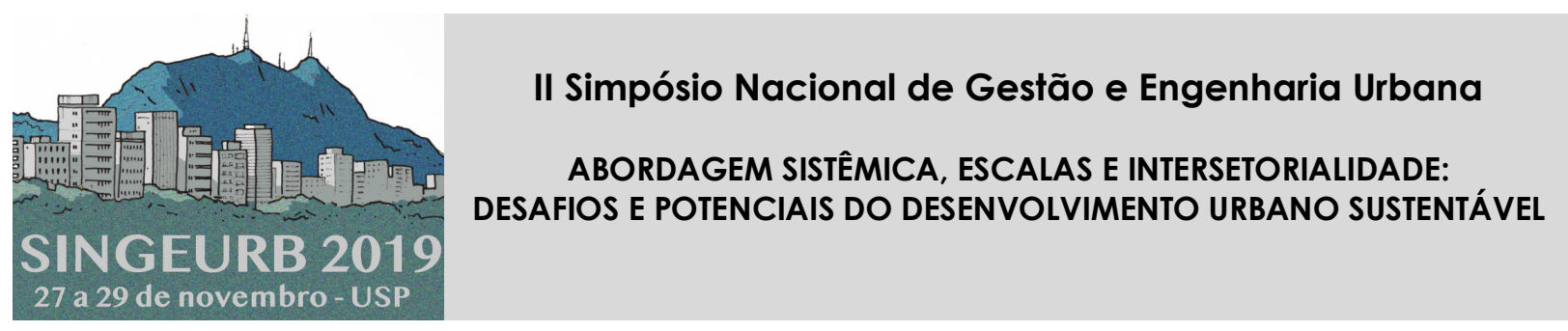

\title{
A valorização territorial e predial em São José do Rio Preto entre os anos 2009 a 20171
}

\section{The land and property valuation in São José do Rio Preto from 2009 to 2017}

\author{
Lisbôa, Cristian Roberto Nazareth ${ }^{\text {; }}$ Castro, Carolina Maria Pozzi de ${ }^{2}$; \\ ' Universidade Federal de São Carlos, Rodovia Washington Luis, km 235 - São \\ Carlos - SP - cristianlisboa@gmail.com \\ 2 Universidade Federal de São Carlos - ccastro@ufscar.br
}

\begin{abstract}
RESUMO
Ao longo das primeiras décadas do século XXI, as cidades de porte médio paulista tornaramse polos regionais atrativos ao mercado imobiliário privado, pois compõem um território único, em função do seu elevado nível de desenvolvimento socioeconômico. Assim sendo, a dinâmica de produção do espaço urbano orientada pelas lógicas de expansão do capital, foram responsáveis por impactos diretos na configuração do espaço intra-urbano, incidindo diretamente na valorização das áreas urbanas. O objetivo deste trabalho é o de demonstrar via Plantas Genéricas de Valores (PGV) de São José do Rio Preto/SP os valores atribuídos a cada porção do território urbano, exprimindo, assim, os movimentos de valorização predial e territorial ocorridos, que corroboram para exprimir uma tendência de ocupação do espaço urbano. Este trabalho compõe um dos capítulos da dissertação de mestrado, e foi realizado por meio do levantamento de fontes primárias, as quais foram categorizadas utilizando o método de classificação de valores por Quebras Naturais (Jenks) e dentre os resultados verificados constatou-se, a intensa pressão imobiliária teve efeitos diretos na PGV e na valorização do território urbano, o trabalho contribui para demonstrar a relação entre os efeitos do uso e ocupação do solo na valorização do espaço urbano.
\end{abstract}

Palavras-chave: Planta genérica de valores, valorização urbana, cidade de porte médio.

\begin{abstract}
Throughout the first decades of the twenty-first century, medium-sized cities in São Paulo became regional centers attractive to the private real estate market, as they comprise a single territory, due to their high level of socioeconomic development. Thus, the dynamics of production of urban space guided by the logic of capital expansion were responsible for direct impacts on the configuration of intra-urban space, directly affecting the valorization of urban areas. The objective of this work is to demonstrate the values attributed to each part of the urban territory via the Generic Values Plants (PGV) of São José do Rio Preto / SP, thus expressing the land and territorial valuation movements that occurred, which corroborate expressing a tendency to occupy the urban space. This paper makes part of the chapters present in the
\end{abstract}

\footnotetext{
${ }^{1}$ LISBÔA, Cristian Roberto Nazareth; CASTRO, Carolina Maria Pozzi de. A valorização territorial e predial em São José do Rio Preto entre os anos 2009 a 2017. In: II SIMPÓSIO NACIONAL DE GESTÃO E ENGENHARIA URBANA: SINGEURB, 2019, São Paulo. Anais... Porto Alegre: ANTAC, 2019.
} 
dissertation, and was conducted through survey of primary sources, which were categorized using the method for breaks Natural values classification (Jenks) and from the results verified it was found, the intense Real estate pressure had direct effects on PGV and on the valorization of urban territory, the work contributes to demonstrate the relationship between the effects of land use and occupation on the valorization of urban space.

Keywords: Generic plant of values, urban valorization, medium-sized city.

\section{INTRODUÇÃO}

Ao longo das últimas décadas as cidades médias do interior paulista tornaram-se territórios únicos e atrativos, dada as transformações econômicas e sociais então vivenciadas, sobretudo em função do desenvolvimento de sua infraestrutura, fluxos de capitais e aumento populacional, que somados a elevação da renda e a consequente redução da pobreza, ampliou a capacidade de consumo destes habitantes, o que possibilitou o acesso ao mercado imobiliário residencial privado, dinamizando a produção mediante a ampliação deste mercado, que atraiu para essas regiões uma gama de empreendedores urbanos, e tais aspectos influenciaram o mercado imobiliário, ao passo que o modelo de urbanização dado por meio da aliança entre a financeirização do setor imobiliário e a forma de produção deste mercado nas definições intra-urbanas migraram das grandes metrópoles, para as diversas cidades brasileiras (CASTRO e SHIMBO, 2010; SANFELICI, 2013b; MELAZZO, 2015).

Destarte, grandes incorporadoras somaram-se as empresas de atuação local/regional e passaram, a extrair suas rendas sob forte apoio das administrações municipais, respaldadas pelas políticas de desenvolvimento econômico nacional. Logo, a intensificação das atividades imobiliárias nas cidades de porte médio induziram "maiores graus de complexidade dos padrões de estruturação urbana, [...] produzindo novas práticas socioespaciais" (MELAZZO, 2015, p. 374), com fortes reflexos na produção do espaço urbano.

Em Rio Preto, entre 2000 a 2015, a área do perímetro urbano aumentou de $85,66 \mathrm{~km}^{2}$ para $135,01 \mathrm{~km}^{2}$, tal qual a escalada dos valores dos imóveis e da terra urbanizada, que acentuam os processos de segregação socioespacial, destarte, o município tem passado por um intenso processo de exploração imobiliária, fenômeno este que foi altamente apoiado pelas gestões públicas locais (LISBÔA, 2019). Portanto, a produção e negociação de novos empreendimentos imobiliários, realizados por empresas de capital aberto ou não, induziram a reestruturação da malha urbana que, por sua vez, implicaram em modificações no padrão de ocupação, e a intensificação de antigos problemas urbanos ligados ao espraiamento urbano e a especulação imobiliária.

\section{VALORIZAÇÃO TERRITORIAL/PREDIAL E SEUS REFLEXOS NA MALHA URBANA}

Tal processo de expansão incide diretamente nas receitas municipais, pois é mediante a transformação do solo rural em urbano e a posse de imóvel localizado na área urbana, que ocorre a cobrança do Imposto Predial e Territorial Urbano (IPTU), cujos valores são estabelecidos pela Planta Genérica de Valores (PGV), que permite uma "avaliação em massa de imóveis" (PAIVA e ANTUNES, 2017, p. 509), isto posto, a municipalidade, com a premissa de se fazer cumprir a função social da propriedade, estabelece por meio da cobrança do IPTU um elemento para "recuperar, ao menos em parte, os custos da urbanização que dá à propriedade o seu valor" (JORGENSEN, 2008, p. 61).

Em 2016, a receita nacional do IPTU foi de R $\$ 31$ bilhões, o imposto é considerado um dos mais rejeitados pelos brasileiros, sendo alvo de constantes polêmicas envolvendo as municipalidades e contribuintes. Frente a impopularidade, diversos municípios não utilizam todo o potencial de arrecadação propiciado, especialmente os de pequeno porte, pois, quanto mais estreita a relação entre o poder público e o munícipe, maior é a probabilidade de embate e desgastes políticos, logo, tais administrações sub-utilizam a captação do imposto, dependendo dos repasses de recursos de outras esferas governamentais (AFONSO e CASTRO, 2014; CARVALHO JUNIOR, 2017). 
Nos municípios mais populosos ocorre o movimento contrário, sobretudo em função do "alto custo administrativo, com grande economia de escala, necessidade de processos sofisticados de avaliações imobiliárias, cadastro atualizado, digitalizado e referenciado, uma procuradoria e auditoria eficientes para cobrança do imposto" (AFONSO, ARAÚJO e NÓBREGA, 2013, p. 25 e 26), impelindo-os a incrementar a captação de receita por meios próprios.

Em São José do Rio Preto, a cobrança do IPTU por meio da PGV ocorre desde 1967, e desde a década de 1980, a municipalidade investe efetivamente na modernização dos instrumentos e ferramentas cartográficas, com vistas a manter revisada e atualizada sua base cadastral imobiliária, cujo objetivo é o de coibir e identificar obras e ampliações clandestina, regularizar a receita por meio da correção de distorções nos lançamentos dos impostos (SOUZA e GALI, 2007) e o ajuste da PGV segundo os movimentos de valorização do mercado imobiliário, frente às mudanças ocorridas na estrutura intra-urbana.

Entre 2000 e 2015, foram arrecadados no município R $\$ 1$ bilhão via cobrança do IPTU (LEME, E., 2008, p. 70; LEME, 2016, p. 80). Afonso, Araújo e Nóbrega (2013, p. 25), apontam que nas "cidades com população acima de 200 mil habitantes, o IPTU tem representado, em média, 9,4\% da receita corrente". Em Rio Preto², entre 2012 e 2015, foi arrecadado um valor próximo ao apontado, uma média de $11,5 \%$, cerca de $R \$ 468,6$ milhões, e o imposto ocupa a quarta posição dentre as principais arrecadações (Tabela 1).

Tabela 1 - Principais Receitas da Administração Direta em SJRP - 2012 a 2015. (Em R \$ milhões)

\begin{tabular}{|c|c|c|c|c|c|c|c|c|c|c|}
\hline \multirow{2}{*}{$\begin{array}{l}\text { Especificação } \\
\text { da Receita }\end{array}$} & \multicolumn{2}{|l|}{2012} & \multicolumn{2}{|l|}{2013} & \multicolumn{2}{|l|}{2014} & \multicolumn{2}{|l|}{2015} & \multicolumn{2}{|c|}{ TOTAL PERÍODO } \\
\hline & RS & $\%$ & RS & $\%$ & RS & $\%$ & RS & $\%$ & RS & $\%$ \\
\hline ICMS & 138,8 & $16,1 \%$ & 161,2 & $17,2 \%$ & 160,7 & $15,2 \%$ & 170,6 & $14,2 \%$ & 631,3 & $19,1 \%$ \\
\hline ISSQN & 108,9 & $12,6 \%$ & 126,2 & $13,5 \%$ & 145,9 & $13,8 \%$ & 163,3 & $13,6 \%$ & 544,3 & $16,5 \%$ \\
\hline Fundeb & 102,8 & $11,9 \%$ & 122,1 & $13,1 \%$ & 130 & $12,3 \%$ & 138,1 & $11,5 \%$ & 493 & $15,0 \%$ \\
\hline IPTU & 95,5 & $11,1 \%$ & 104,7 & $11,2 \%$ & 128,5 & $12,2 \%$ & 139,9 & $11,7 \%$ & 468,6 & $14,2 \%$ \\
\hline SUS & 81,9 & $9,5 \%$ & 87,7 & $9,4 \%$ & 97,6 & $9,2 \%$ & 101,4 & $8,5 \%$ & 368,6 & $11,2 \%$ \\
\hline IPVA & 65,5 & $7,6 \%$ & 71 & $7,6 \%$ & 78,3 & $7,4 \%$ & 82,8 & $6,9 \%$ & 297,6 & $9,0 \%$ \\
\hline FPM & 35,6 & $4,1 \%$ & 39,3 & $4,2 \%$ & 39,7 & $3,8 \%$ & 44,5 & $3,7 \%$ & 159,1 & $4,8 \%$ \\
\hline ITB| & 26,9 & $3,1 \%$ & 33,3 & $3,6 \%$ & 33,3 & $3,2 \%$ & 29,9 & $2,5 \%$ & 123,4 & $3,7 \%$ \\
\hline $\begin{array}{l}\text { IR retido } \\
\text { Fonte }\end{array}$ & 22,5 & $2,6 \%$ & 27,1 & $2,9 \%$ & 32,7 & $3,1 \%$ & 36,7 & $3,1 \%$ & 119 & $3,6 \%$ \\
\hline Dívida Ativa & 11,5 & $1,3 \%$ & 21,3 & $2,3 \%$ & 22 & $2,1 \%$ & 38 & $3,2 \%$ & 92,8 & $2,8 \%$ \\
\hline TOTAL ANO & 863,4 & 100 & 935,1 & 100 & 1.056 & 100 & 1.198 & 100 & 3.297 & 100 \\
\hline
\end{tabular}

Fonte: $O$ autor a partir de dados obtidos em LEME, 2016, p. 80.

O Gráfico 1 exprime o preço médio anual $/ \mathrm{m}^{2}$ e a variação da elevação dos valores relativos a PGV de São José do Rio Preto entre 2009 a 2017. Na PGV Predial, pode ser verificado uma

\footnotetext{
${ }^{2}$ A título de estabelecer uma relação de valor médio do IPTU por habitante, em 2018 a Controladoria Geral do Município de Sorocaba realizou uma pesquisa dentre dez cidades do estado com perfil sociodemográfico similar a Sorocaba e constatou que, Campinas apresenta o maior valor, $R \$ 472$, seguida por Ribeirão Preto ( $R \$ 469)$, Itu ( $R \$ 373)$, São José do Rio Preto foi o quarto mais alto ( $R \$ \mathbf{3 6 3 , 0 0}$ ), Jundiaí ( $R \$ 350)$, Votorantim ( $R \$ 283)$, São José dos Campos ( $R \$ 276)$, Piracicaba ( $R \$ 245)$ e pôr fim a cidade de Bauru (R\$238), o valor mais baixo dentre as cidades pesquisadas (ASSIS, 2018).
} 
crescente valorização do preço médio, uma variação de 55,3\%, reflexo da valorização dos imóveis no território. Quanto aos valores da PGV Territorial, verificou-se sua elevação até 2012, em 2013 e 2014 ocorreram sucessivas reduções nos valores médios, apresentando, nos anos subsequentes ligeiras elevações decorrentes de sucessivas correções realizadas.

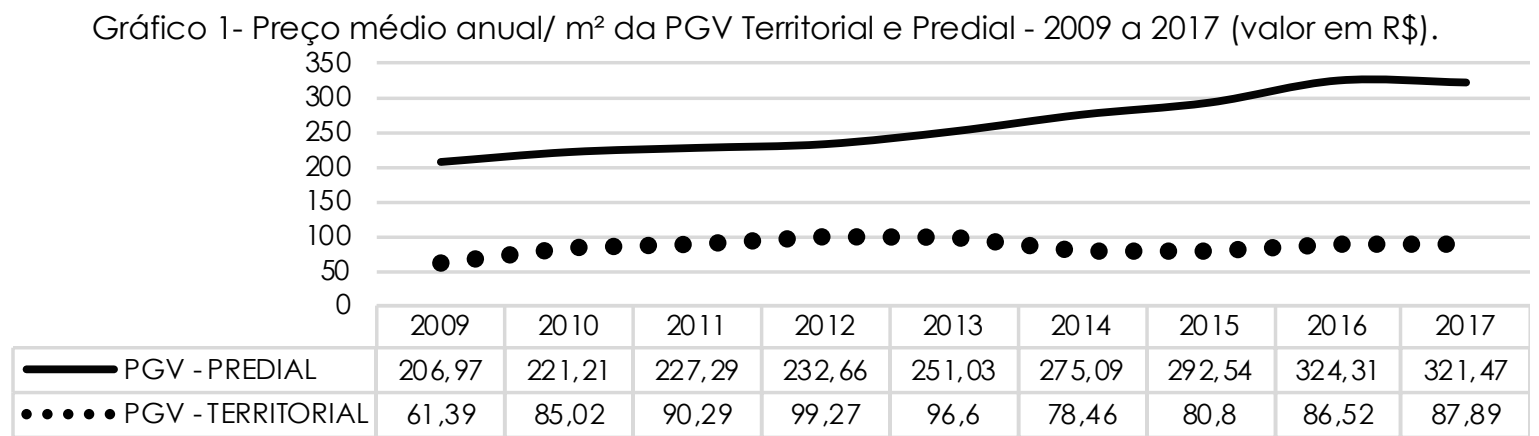

Fonte: O autor a partir da análise e transcrição dos dados presentes nos mapas de PGV fornecidos pela EMPRO.

Em sequência, seguem as Figuras 1, 2, 3 e 4, que demonstram ${ }^{3}$ no território a evolução da PGV para os anos verificados no Gráfico 1. O principal objetivo é demonstrar os valores atribuídos a cada porção do território urbano da cidade, exprimindo, assim os movimentos de valorização predial e territorial ocorridos recentemente que corroboram para exprimir uma tendência de ocupação do espaço urbano, pois influenciam na definição do perfil econômico do indivíduo que ali habita, uma vez que os valores que incidem sobre a propriedade são fatores excludentes.

É possível verificar que as áreas que apresentam os maiores valores na PGV estão localizadas na porção Sul-Centro-Leste, regiões que historicamente tiveram sua exploração e desenvolvimento com vistas a atender as camadas de alta renda (BUENO, 2003; TEODÓZIO, 2008). Em tais regiões estão localizados os primeiros bairros que formaram o município, assim como os principais loteamentos e condomínios fechados destinados às classes alta e média, são áreas dotadas de vias de acesso rápido, ocorrem os principais centros de compras, equipamentos de prestação de serviços públicos/privados de saúde, lazer, cultura e consequentemente, concentram maior oferta de trabalho.

Nestas localidades, em praticamente todos os anos, os valores atingem o teto, em especial em 2009 (vide Figura 1), cujo maior valor para a propriedade urbana com edificação é de $\mathrm{R} \$ 417,87 / \mathrm{m}^{2}$ sendo este valor tomado como base de cálculo para prédios localizados nos loteamentos fechados localizados nas Regiões Administrativas (RAs) 53 e 54 a Leste e RAs 21 e 22 a Sul. Quanto ao valor para a propriedade urbana sem edificação, a RA01 - Centro é a que apresenta os maiores valores, de $\mathrm{R} \$ 654,68 / \mathrm{m}^{2}$ (referente ao o centro histórico) e, para o entorno, o valor de $\mathrm{R} \$ 374,40 / \mathrm{m}^{2}$. Em decorrência da adoção de um Plano Diretor inexpressivo esse é um dos poucos mecanismos que 'forçam' os proprietários de terrenos a proceder a sua ocupação, uma vez que os valores para $\circ \mathrm{m}^{2}$ da propriedade urbana edificada na região central é de $R \$ 242,35$.

Na porção Norte e em regiões periféricas, incidem menores valores, sobretudo no que diz respeito à PGV territorial, nessas regiões estão inseridos os conjuntos habitacionais e loteamentos voltados às classes populares, tal medida contribui para manter tais áreas ociosas corroborando para a formação de banco de terras. Em 2012 (Figura 2), a tendência segue um padrão muito similar ao ocorrido em 2009.

\footnotetext{
${ }^{3}$ A gradação dos valores hora apresentados partem do verde escuro, para regiões que apresentam o menor valor $\mathrm{R} \$ / \mathrm{m}^{2}$, para o vermelho, para as regiões com maior valor $\mathrm{R} \$ / \mathrm{m}^{2}$.
} 
Figura 1 - PGV Predial e Territorial de São José do Rio Preto - 2009.

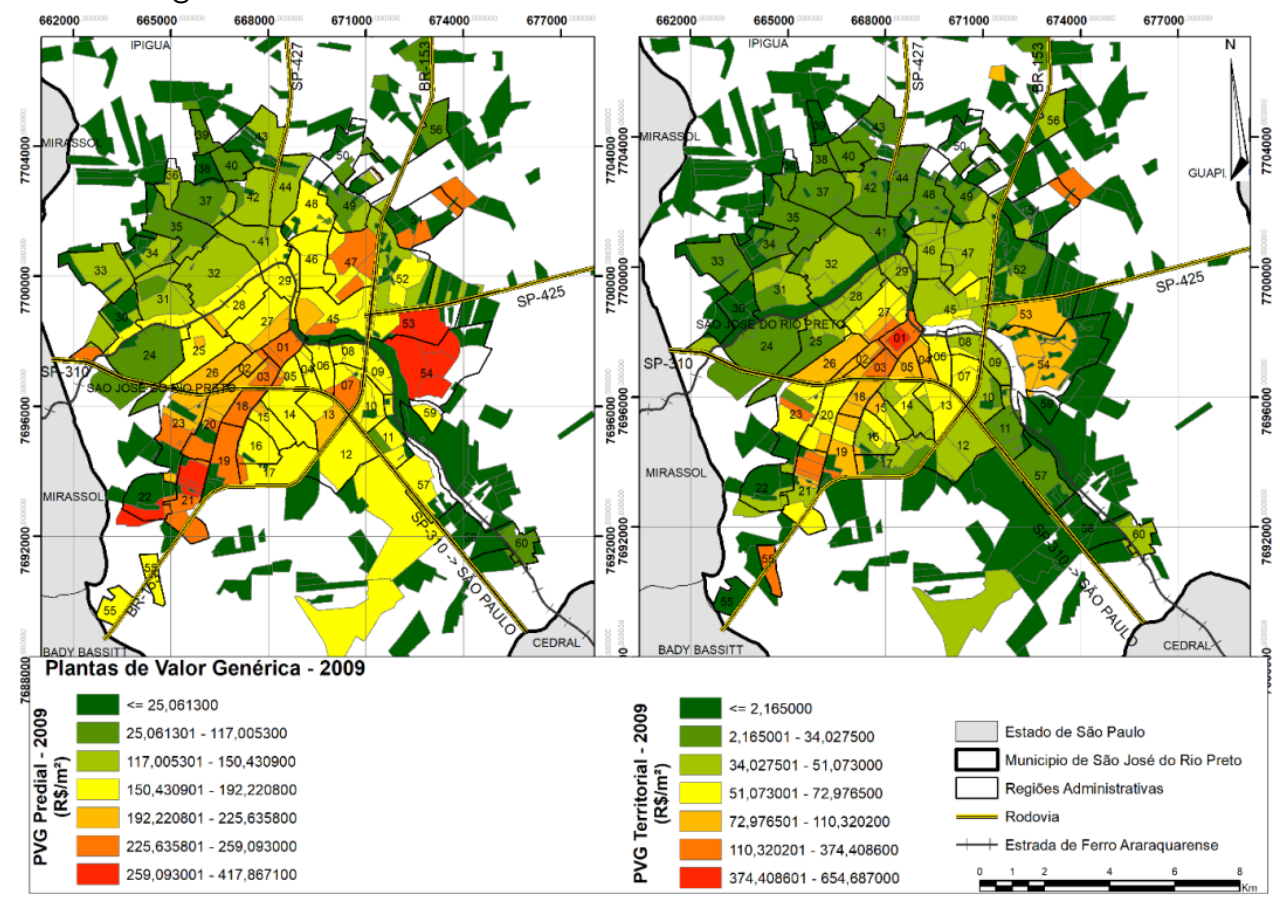

Fonte: $O$ autor a partir de dados da prefeitura.

Figura 2 - PGV Predial e Territorial de São José do Rio Preto - 2012.

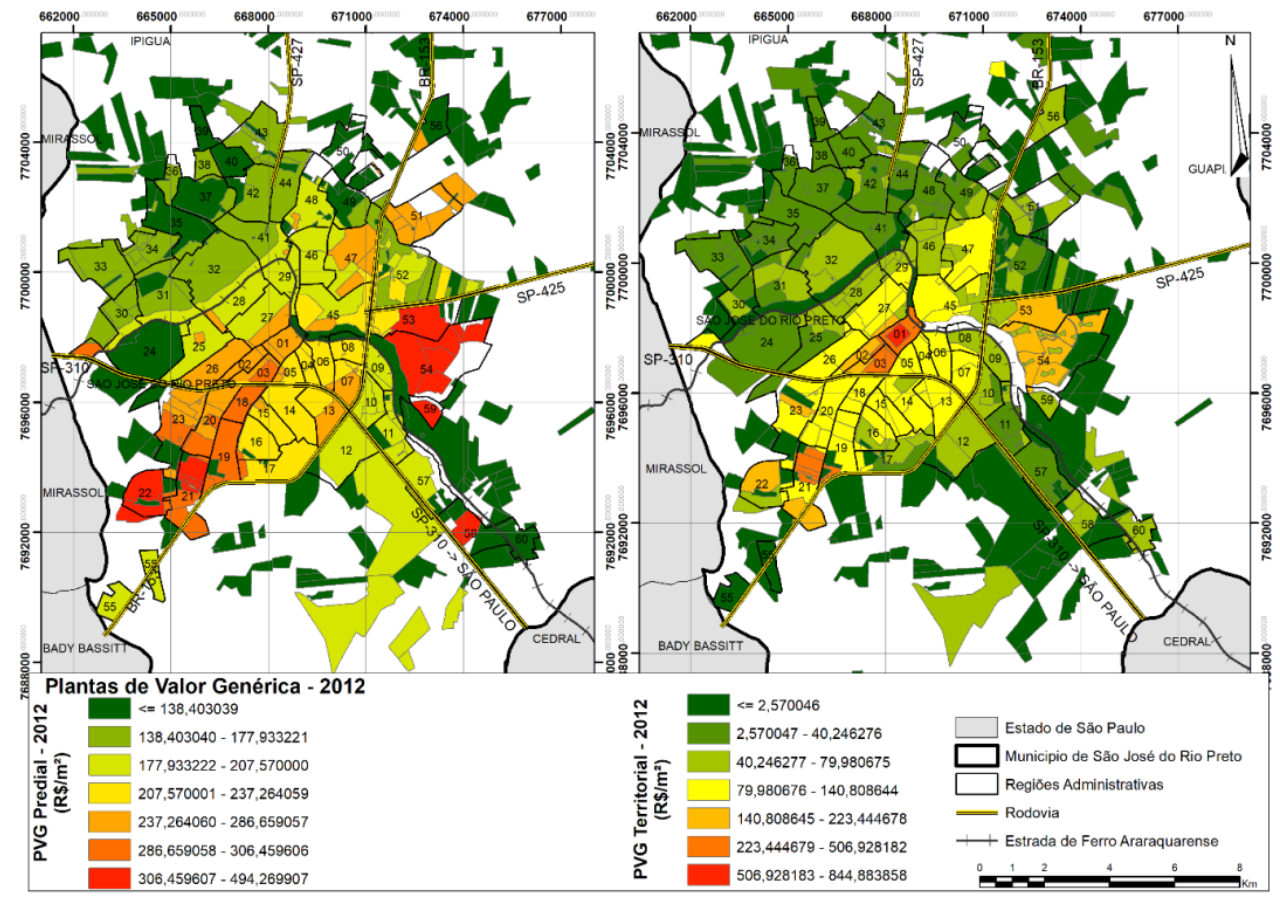

Fonte: $O$ autor a partir de dados da prefeitura.

Os reflexos da dinamização após o boom da construção civil ocorrido em 2009, surtiu efeito nos anos posteriores, decorrente da intensa atuação de diversos empreendedores urbanos, os quais valeram-se do processo de produção do espaço e sua urbanização para a apropriação da mais-valia e, consequentemente, a tradicional forma de ocupação vigente no território é modificada. Este fato está expresso pela PGV de 2015 (Figura 3), a qual em comparação aos anos anteriores, demonstra a valorização ocorrida nos imóveis prediais 
localizados ao norte do município, região que passou por diversas transformações urbanísticas estruturais e sociais, tornando-a atrativa ao mercado imobiliário (LISBÔA, 2019).

Figura 3 - PGV Predial e Territorial de São José do Rio Preto - 2015.

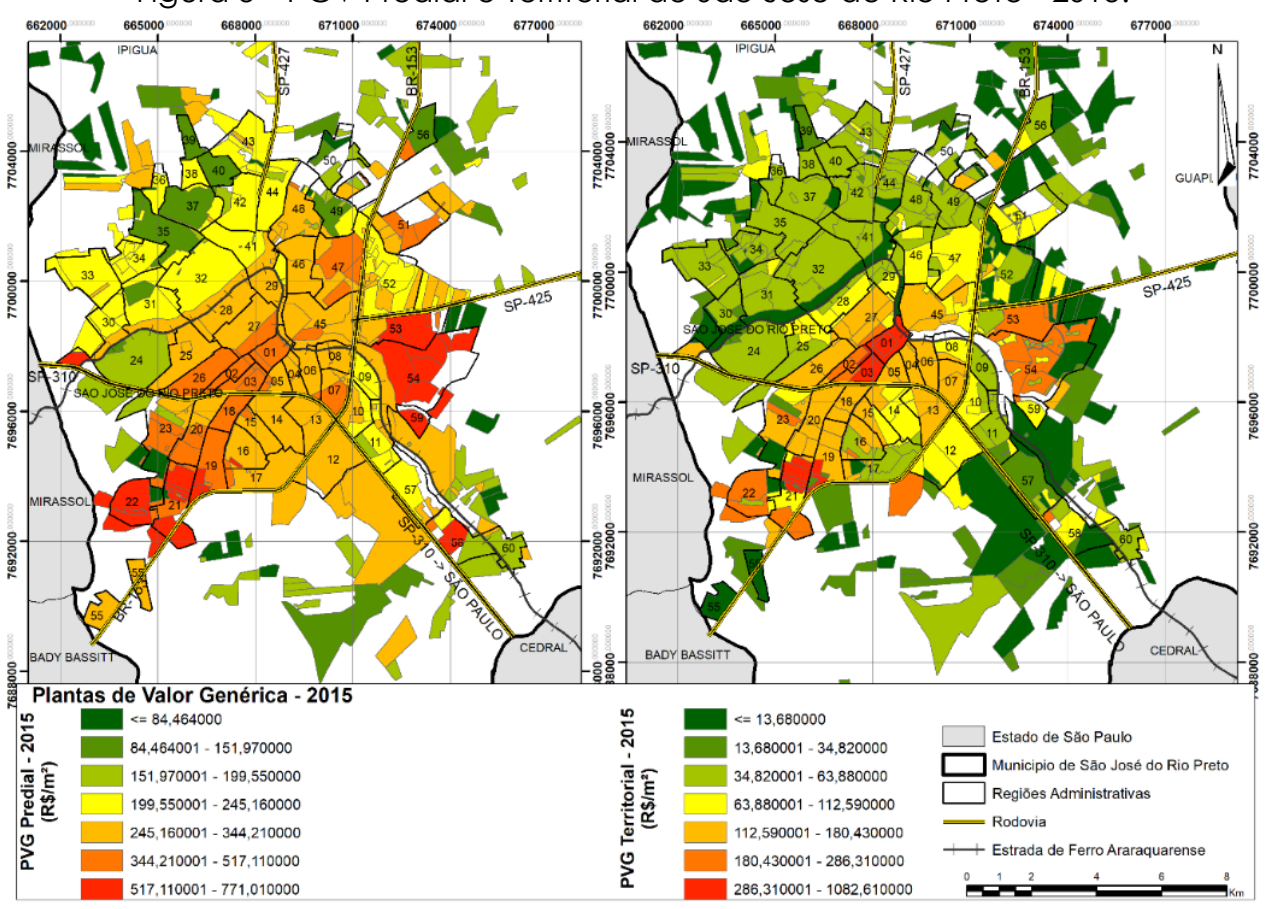

Fonte: $O$ autor a partir de dados da prefeitura.

Por fim, a Figura 4 apresenta as correções realizadas na PGV e resume o padrão econômico de ocupação no território rio-pretense. A contínua incidência dos altos valores é visualizada no eixo Sul-Centro-Leste e, a medida em que se afasta deste vetor, os valores passam a diminuir gradualmente.

Figura 4 - PGV Predial e Territorial de São José do Rio Preto - 2017.

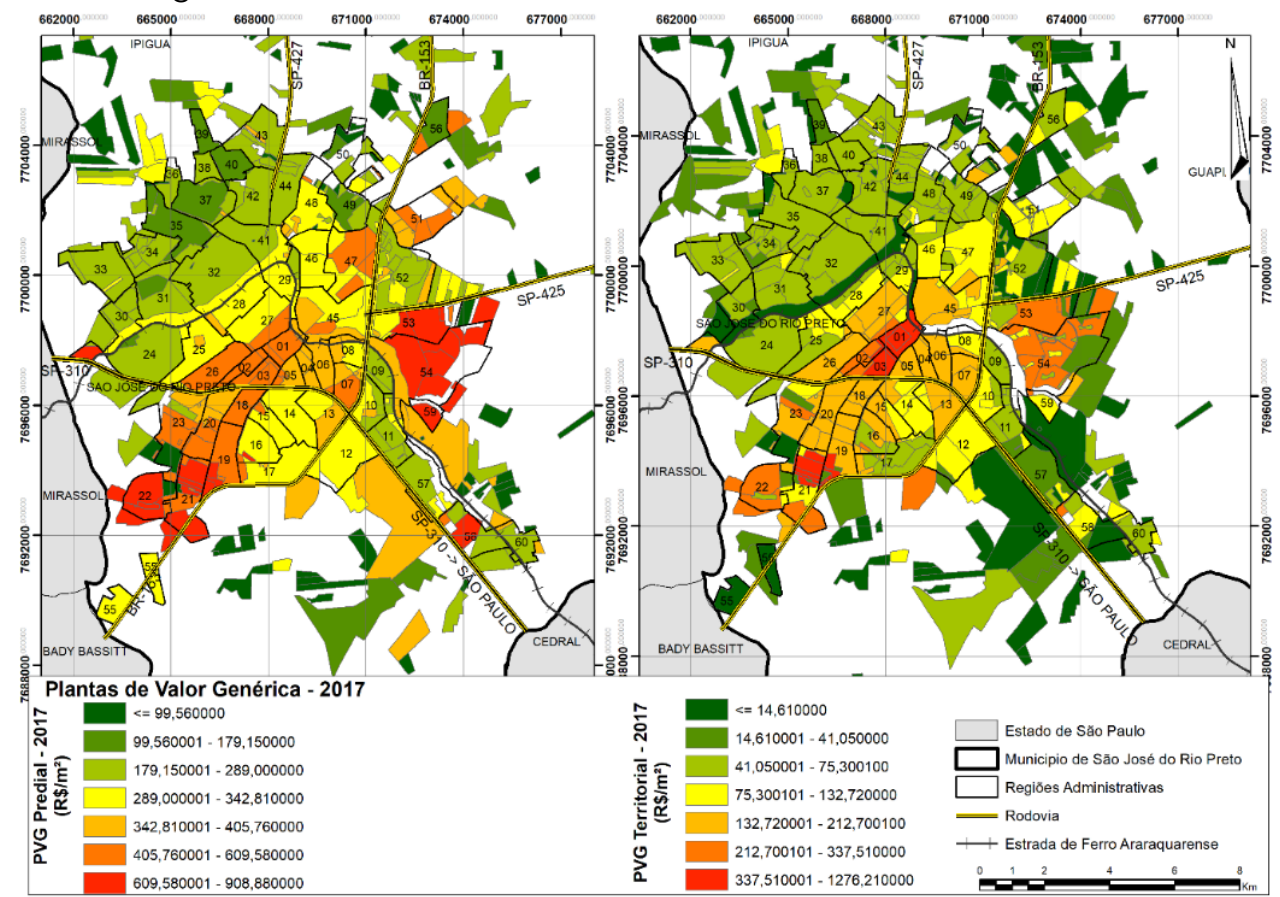

Fonte: O autor a partir de dados da prefeitura. 


\section{CONCLUSÕES}

A PGV pode ser um mecanismo preliminar para a compreensão de tendências e dinâmicas do mercado imobiliário local, assim como para a ocupação do espaço intra-urbano, pois são reflexos dos valores na escala em que ocorre o seu consumo, pois, para sua elaboração, variáveis como o preço dos imóveis e a infraestrutura existente são consideradas, incidindo diretamente na valoração ou não de determinadas áreas. Logo, ao associar a evolução da PGV no município à reflexão de autores sobre a estruturação intra-urbana, verificou-se a sequente valorização dos imóveis localizados na porção Leste-Centro-Sul, regiões que concentram os estratos de maior rendimento, ademais, em função das recentes dinâmicas imobiliárias, notou-se a valoração em áreas localizadas ao norte. Isto posto, a PGV corrobora para demonstrar as recentes mudanças ocorridas no espaço intra-urbano da cidade, no entanto estudos complementares devem ser realizados para identificar a interação desta valorização com a produção do espaço e suas tendências.

\section{REFERÊNCIAS}

AFONSO, J. R.; ARAÚJO, E. A.; NÓBREGA, M. A. R. O IPTU no Brasil: um diagnóstico abrangente. Rio de Janeiro: FGV, v. 4, 2013.

AFONSO, J. R.; CASTRO, K. P. IPTU e Finanças Públicas Municipais no Brasil: Dificuldades e Potencial. São Paulo: FGV/ IBRE, 2014.

ASSIS, C. IPTU de Sorocaba é menor entre 10 cidades avaliadas em estudo. Prefeitura de Sorocaba, 2018. Disponivel em: <http://agencia.sorocaba.sp.gov.br/iptu-de-sorocaba-emenor-entre-10-cidades-avaliadas-em-estudo/>. Acesso em: 18 dez 2018.

BUENO, J. C. L. A expansão física de São José do Rio Preto de 1980 A 2000. São Paulo: Tese (Doutorado) - Faculdade de Arquitetura e Urbanismo - Universidade de São Paulo, 2003.

CARVALHO JUNIOR, P. H. B. Imposto Predial e Territorial Urbano (IPTU). Brasília:

Fenafisco/Anfip, 2017.

CASTRO, C.; SHIMBO, L. Das cooperativas autofinanciadas às construtoras e incorporadoras de capital aberto: a ampliação do mercado habitacional. Revista Brasileira de Estudos Urbanos e Regionais, v. Vol. 12, n. 2, p. p. 53-74, 2010.

JORGENSEN, P. O mercado imobiliário e a formação dos preços do solo. In: PINHEIRO, O. M.; COORD. Acesso à terra urbanizada implementação de Planos Diretores e regularização fundiária plena. Florianópolis; Brasília: UFSC; Ministério das Cidades, 2008. Cap. Aula 2, p. 5174. ISBN 978-85-7426-018-1.

LEME, E. Conjuntura Econômica de São José do Rio Preto. 23a. ed. São José do Rio Preto: Secretaria Municipal de Planejamento Estratégico, Ciência, Tecnologia e Inovação, 2008.

LEME, E. Conjuntura Econômica de São José do Rio Preto. $31^{a}$. ed. São José do Rio Preto: Secretaria Municipal de Planejamento Estratégico, Ciência, Tecnologia e Inovação, 2016.

LISBÔA, C. R. N. A produção residencial por empresas privadas: Sua influência no território urbano de São José do Rio Preto/ SP de 2000 a 2015. Dissertação (Mestrado) Programa de Pós-Graduação em Engenharia Urbana da Universidade Federal de São Carlos. São Carlos. 2019.

MELAZZO, E. INTERAÇÕES, COMBINAÇÕES E SINERGIAS: PRODUÇÃO DO ESPAÇO URBANO, DINÂMICAS IMOBILIÁRIAS E O PROGRAMA MINHA CASA MINHAVIDA EM CIDADES MÉDIAS BRASILEIRAS. In: BELLET, C., et al. Urbanización, producción y consumo en ciudades medias / 
intermedias - Urbanização, produção e consumo em cidades médias / intermediárias.

Lleida: Edicions de la Universitat de Lleida, v. 1, 2015. Cap. 6, p. 373-396.

PAIVA, A.; ANTUNES, A. F. B. GERAÇÃO DE PLANTA DE VALORES GENÉRICOS A PARTIR DO CADASTRO TERRITORIAL URBANO. Revista Brasileira de Cartografia, Rio de Janeiro, v. 3, n. 69, p. 505-518, mar 2017.

SANFELICI, D. Financeirização e a produção do espaço urbano no Brasil: uma contribuição ao debate. EURE, Santiago, 2013b. 27-46.

SOUZA, C. H. G.; GALI, B. GEOPROCESSAMENTO APLICADO NO MUNICÍPIO DE SÃO JOSÉ DO RIO PRETO: DO CADASTRO AO PLANO DIRETOR. II Simpósio Brasileiro de Geomática e V Colóquio Brasileiro de Ciências Geodésicas, Presidente Prudente, 24-27 jul 2007. 604-610.

TEODÓZIO, D. Do sertão à cidade: planejamento urbano em São José do Rio Preto: dos anos 50 aos anos 2000. São Carlos: Tese (Doutorado) - Programa de Pós-Graduação em Arquitetura e Urbanismo e Área de Concentração em Teoria e História da Arquitetura e do Urbanismo - Escola de Engenharia de São Carlos da Universidade de São Paulo, 2008. 